\title{
Nurses' Knowledge and Attitudes towards Pain Management in Children Admitted in the Paediatric Department of Queen Elizabeth Central Hospital, Blantyre, Malawi
}

\author{
Edina T. Kholowa ${ }^{1}$, Angela F. Chimwaza ${ }^{2}$, Maureen D. Majamanda², Alfred O. Maluwa² \\ ${ }^{1}$ Nursing and Midwifery Department, Malamulo College of Health Sciences, Malawi Adventist University, Thyolo, Malawi \\ ${ }^{2}$ Faculty of Nursing, Kamuzu College of Nursing, University of Malawi, Blantyre, Malawi \\ Email: taziona.limbani@gmail.com, afchimwaza@kcn.unima.mw, mdmajamanda@kcn.unima.mw, aomaluwa@kcn.unima.mw
}

How to cite this paper: Kholowa, E.T., Chimwaza, A.F., Majamanda, M.D. and Maluwa, A.O. (2017) Nurses' Knowledge and Attitudes towards Pain Management in Children Admitted in the Paediatric Department of Queen Elizabeth Central Hospital, Blantyre, Malawi. Journal of Biosciences and Medicines, 5, 46-59.

https://doi.org/10.4236/jbm.2017.56005

Received: March 31, 2017

Accepted: June 24, 2017

Published: June 27, 2017

Copyright () 2017 by authors and Scientific Research Publishing Inc. This work is licensed under the Creative Commons Attribution International License (CC BY 4.0).

http://creativecommons.org/licenses/by/4.0/

\begin{abstract}
Background: Inadequate pain management is a problem in hospitalized children. Objectives: To explore knowledge and attitudes of nurses in management of pain in children. Methods: A descriptive design using qualitative methods was used to conduct the study. 17 nurses with prior pain management training were interviewed using a semi-structured interview guide. Ethical approval was obtained from College of Medicine Research and Ethics Committee. Data were analysed using thematic content analysis. Results: Nurses had some knowledge of pain assessment methods, treatment and use of morphine. Gaps, however, existed on how to use pain assessment scales, analgesics to use at each step of the WHO analgesic ladder, and how to effectively use morphine for pain relief. Although most nurses had positive attitudes towards children's pain and use of morphine, negative attitudes were evident in some nurses regarding administration of morphine to neonates or acutely ill children. Conclusion and Implications: The study has revealed knowledge and attitude gaps which may reflect deficiencies in the pain education nurses received, non-availability of pain scales and lack of support for nurses to link theory with practice. Nurse leaders are challenged to provide repeated comprehensive education for nurses on pain assessment and management. Furthermore, user friendly pain scales should be developed, and nurses educated and demonstrated on their use. In addition, opportunities for supportive supervision with nurses in the clinical setting should be created for linkage of theory and practice.
\end{abstract}

\section{Keywords}

Children, Pain Assessment, Caregivers/Parents/Guardians, Nurses, Pain 


\section{Introduction}

Pain management is a major problem in hospitalized children [1] [2]. Poorly relieved pain has been associated with negative outcomes including delayed recovery and increased likelihood of early death in HIV infected children [3]. Despite knowledge of these consequences, inadequate pain management in hospitalized children is widely documented [4] [5] [6] and [7].

Adequate pain treatment requires accurate pain identification and determination of severity [8] [9]. Pain assessment methods such as self-reports, for example Faces scale [10]; behaviour observation, for example the FLACC scale (Facial expression, Legs, Activity, Cry and Consolability) scale [11] and caregiver reports may be used. Once identified, several measures are used to treat pain. Administration of analgesics according to the WHO Analgesic Ladder is one of the recommended methods [12] [13]. For maximum effectiveness, analgesics must be administered "by the clock", "by mouth" and "by the patient" in combination with adjuvant drugs such as sedatives as needed [12] [13].

Nurses' inadequate knowledge of pain assessment and treatment has been found to contribute to inadequate pain management [1] [5] [6] and [14]. Negative attitudes towards pain management have also been implicated [6] [7] [15] [16] and [17]. To improve nurses' knowledge and change their attitudes towards children's pain management, educational interventions have been carried out in different settings. In a number of studies, pain education sessions for nurses resulted in improved pain management practices [18] [19]. Similarly, a pain education program was conducted at QECH for nurses [2]. Unfortunately, this did not lead to improved pain management practices according to the researcher's observations.

This study was conducted to explore nurses' knowledge and attitudes on children's pain management to identify strategies for improving pain management practices in the paediatric department. The study was carried out in response to a pain education workshop which took place in 2009 to equip nurses with pain management knowledge and appropriate attitudes. Following a needs assessment conducted in the department by the researcher, it was found that children's pain was being inadequately managed and the study sought to find out whether knowledge and attitudes were still a problem affecting pain management.

\section{Methodology}

The study used a descriptive design utilizing qualitative methods. In-depth interviews were conducted using a semi structured interview guide developed by the researcher to gain insights into nurses' knowledge and attitudes towards children's pain management. The interview guide contained questions on knowledge of pain management, attitudes towards pain management and strate- 
gies to improve pain management in children (see Appendix A)

The study was conducted at the peadiatric department of Queen Elizabeth Central Hospital (QECH) from August to October 2012. QECH is the largest referral hospital in Malawi which serves patients from across Malawi and its borders. The hospital was selected because it offers a wide variety of services to children with acute and chronic conditions and had a good number of nurses who attended pain management training. Purposive sampling was employed to consciously select respondents who had attended children's pain management training while working in the peadiatric department. Over 30 had been trained but only 22 were still working in the department at the time of the study. Of this population, only 17 participants consented to take part in the study. Data saturation was reached after 13 participants had been interviewed but still, 4 more participants were interviewed to confirm saturation.

Inclusion and exclusion criteria

All nurses who underwent children's pain management training were included, while those trained but working in adult wards; students; nurses who had been in paediatric department less than 6 months were excluded as they were considered not to have enough experience in managing pain in children.

In-depth interviews were conducted within the hospital premises. Interviews were tape-recorded to capture all information and then tape-recorded interviews were transcribed word for word for accuracy and completeness of data. The transcripts were then safely kept by the researcher for reference during analysis. Thematic content analysis as proposed by Anderson [20] and Braun and Clarke [21] was used to analyze data. Transcripts were read several times, sentences with relevant information identified, codes and categories of information developed and finally themes and subthemes generated. These were later discussed.

To protect the research participants, ethical approval to carry out the study was obtained from the College of Medicine Research and Ethics Committee. The Hospital Director, the head of paediatric department and the Unit Nurse Manager gave permission to conduct the study at QECH. Prior to each interview, informed consent was obtained from each participant. Information given to participants included issues of privacy and confidentiality, anonymity, as well as benefits and risks of the study.

\section{Results}

\subsection{Demographic Characteristics (Table 1)}

17 participants were interviewed. Majority had over seven years working experience. There were 14 Enrolled Nurses and Nursing and Midwifery Technicians and three (3) Registered Nurses.

Previous training

13 participants attended the trainings conducted by Umodzi Palliative Care Team while three attended a pain education workshop, pain management in children with burns and other Continuous Professional Development sessions on pain. The duration of the trainings ranged from two hours to three days (Table 2). 
Table 1. Summary of demographic characteristics.

\begin{tabular}{|c|c|}
\hline Year of Qualification: & Numbers \\
\hline 1975-1985 & 3 \\
\hline 1986-1995 & 5 \\
\hline $1996-2005$ & 2 \\
\hline $2006-2012$ & 7 \\
\hline \multicolumn{2}{|c|}{ Years of Experience working in Paediatric Department } \\
\hline $0-<3$ & 9 \\
\hline $3-<6$ & 3 \\
\hline $6-<9$ & 2 \\
\hline $9-<12$ & 2 \\
\hline $12-<15$ & 1 \\
\hline \multicolumn{2}{|l|}{ Ward currently working in } \\
\hline Accident and Emergency unit & 2 \\
\hline Burns unit & 1 \\
\hline Malaria research & 2 \\
\hline Nutritional rehabilitation & 1 \\
\hline Paediatric orthopaedic & 2 \\
\hline Paediatric nursery & 3 \\
\hline Special care & 5 \\
\hline Umodzi palliative care team & 1 \\
\hline
\end{tabular}

Table 2. Training attended by nurses.

\begin{tabular}{ccc}
\hline Type of Training & $\begin{array}{c}\text { Number of } \\
\text { Participants }\end{array}$ & $\begin{array}{c}\text { Duration of } \\
\text { Training }\end{array}$ \\
\hline Umodzi Palliative Care Team & 13 & 8 hours \\
Pain education workshop & 2 & 2 hours \\
Pain management in burns in children & 2 & 3 days \\
Other Continuous Professional Development sessions & 3 & 2 hours \\
Attended more than one training & 3 & \\
\hline
\end{tabular}

\subsection{Qualitative Analysis}

The themes that emerged were: inadequate pain assessment and treatment of pain. Under inadequate pain assessment, the following subthemes emerged: Inadequate knowledge of pain assessment methods, Attitudes towards pain and pain assessment in children; while the following subthemes came under treatment of pain: 
Knowledge of pain treatment methods, inadequate knowledge of the WHO analgesic ladder and Nurses' knowledge and attitudes towards morphine use in children.

\subsubsection{Inadequate Pain Assessment}

While all participants agreed that pain assessment was one of their roles, they acknowledged that pain management was inadequate due to inadequate assessment. Subthemes that emerged were inadequate knowledge of pain assessment methods, inadequate knowledge of using pain assessment scales, and attitudes towards pain assessment.

\section{Inadequate knowledge of pain assessment methods.}

Participants were asked how they identified pain in children. Most participants reported that they assessed pain by observing the child's behaviors such as an uncontrollable cry, facial expression and posture. Other frequently mentioned methods were self-reports from patients(children who could speak), and reports from the guardian. Other nurses stated that they knew a child was in pain just by knowing the patients' diagnosis or surgical intervention. Others reported using a pain checklist on alternate days to evaluate response to morphine and the need to adjust its dosage in children with burns. No participant mentioned use of physiological measures or vital signs to assess pain. In addition, majority of participants did not know how to use the FLACC or Faces scales of pain assessment. Few reported that they had heard about it but had forgotten what it was. Those who reported knowing and using it had inaccurate knowledge of rating pain using the scale. One of the participants said:

"We learnt, but not very much, because they said the Faces scale is ... difficult to interpret. ...But I know sometimes you can use that scale where there are faces so you can tell if the child is happy, unhappy, depressed, in pain... but we were not told much because in our setting we don't have those scales" (Participant 11).

Unavailability of the scales seemed to have contributed to lack of knowledge as well.

\section{Attitudes towards pain and pain assessment in children.}

To assess nurses' attitudes towards pain and pain assessment, participants were asked about their views concerning pain assessment in children. Most participants had positive attitudes towards pain and its identification in children because they stated that children felt as much pain as adults and are able to express their pain though differently from adults. They also added that most children are unable to report pain but the nurse has responsibility to identify pain. Generally, participants considered self-reports as the most reliable form of pain assessment and therefore it was a challenge for children who would not speak as expressed in the following statement:

“...some children they don't cry anyhow while others, when any pain comes, they cry so you can tell that this one is 'feeling pain'. There was a 
child who went for laparotomy for obstruction. It was terrible! The child, when he came from theatre, couldn't cry... (He was) just ever sleeping... but was supposed to receive pethidine as ordered. So we were giving it, but the child didn't cry... or show that he was feeling any pain" (Participant 1).

Nurses working in paediatric nursery expressed difficulty in identifying pain in babies and were concerned that they could be treating pain inadequately. In contrast, nurses working in emergency unit lamented of the few opportunities to apply what they learned because patients did not stay long in the department as they would either go home after treatment or be transferred into the wards after emergency care. One nurse who reported to have tried using the Faces scale said children were not able to understand what she wanted them to do and she stopped using it. Others demonstrated negative attitude towards pain when they said some children cried anyhow just to seek attention from their caregivers and that they feel less pain than adults.

\subsubsection{Treatment of Pain}

All participants stated that they treated pain when they identified it. Subthemes that emerged were: Knowledge of pain treatment methods and Nurses' knowledge and attitudes towards morphine use in children.

\section{Knowledge of pain treatment methods}

Participants generally demonstrated knowledge of pain treatment methods through their description of pharmacological methods of treating pain. Most participants, however, had to be prompted to mention non-pharmacological pain interventions.. Regarding analgesics, participants had knowledge of different analgesics and when to use them. Challenges to adequate pain management were noted in areas of inadequate knowledge of the WHO analgesic ladder as well as knowledge and attitudes towards use of morphine in children.

\section{Inadequate knowledge of the WHO analgesic ladder.}

Participants' knowledge of the WHO analgesic ladder was assessed. Majority reported that they knew about it from their pain education sessions though a few reported to have forgotten what it was. Those who knew it were confused regarding the type of analgesics to use in the second and third steps of the ladder. One Registered Nurse Midwife described the ladder as follows:

“... the (WHO analgesic) ladder involves the medication that you give to eradicate pain... For example, you may start at the bottom ...with giving paracetamol for a patient who has little pain. Then (for) moderate pain you may give brufen (or) diclofenac. Then if the patient has severe pain that is when you go to the last ladder of giving morphine, pethidine ... others may give codeine" (Participant 15).

Only one participant mentioned use of anticonvulsants to provide a calming effect on a child in pain.

Nurses' knowledge and attitudes towards morphine use in children.

When asked to explain what they knew about morphine, majority showed that 
they had knowledge of morphine, its indications, and side effects. Constipation, for example, was mentioned as a major side effect of morphine resulting from prolonged use and that bisacodyl was usually prescribed to counteract it. Only a few, mentioned that morphine had to be administered regularly, with doses adjusted according to a child's response and should not be withdrawn abruptly.

When asked about their views on morphine use in children, majority acknowledged that morphine is a good strong painkiller that provides relaxation to children experiencing severe pain. Some participants also expressed satisfaction with its use because it had improved pain management in children. Regardless of positive attitudes, a few participants expressed fear that morphine caused addiction and drowsiness and that the drowsiness led to inability to feed, making some children to become sicker and die. One senior enrolled nurse commented this:

“... most of those children that are prescribed morphine are terminally sick and in terrible pain. Those ones I think they can get the morphine but not the children that come with malaria, meningitis. I don't think it's right to give them morphine ... they can be addicted ... and they don't have severe pain ..." (Participant 14).

It was observed that these fears were more prominent in older and more experienced nurses. Some younger nurses feared administering morphine due to threats from their colleagues that they would facilitate death in a child if they administered it.

\section{Discussion}

Participants in this study were found to have knowledge of pain assessment and treatment. They, however, had deficiencies in use of pain scales and other methods of pain assessment. Furthermore, other pain assessment methods such as physiological indicators and vital signs seemed unknown. Similar findings have also been reported in other studies [6] [16] and [22]. Inability to assess pain therefore, meant nurses may not have been giving appropriate treatment according to pain severity. Consequently, children were likely to endure untreated pain and its effects such as prolonged hospital stay, and long term psychological manifestations [22] [23]. The study in addition revealed inadequate knowledge of the WHO analgesic ladder and drugs to use at each step of the ladder. Lack of knowledge of pharmacological and non-pharmacological pain interventions has similarly been documented [19] [24].

Although all participants had prior training in pain management, a number of factors could have affected retention of this knowledge. Firstly, trainings were conducted in different forums which meant they could have been taught by different people on different pain issues. In addition, the training period ranged from two hours to three day sessions which meant presenters had little time to present pertinent issues regarding pain which could also have affected participants' understanding. Ellis et al. [18] and Howell et al [25] in their studies 
showed that pain management education is vital for improving nurses' knowledge and practices only for a short duration and declines with time if education is not sustained. According to Guardini et al., Ellis et al., and Biceck, [7] [18] [26] sustained knowledge is associated with comprehensive pain education conducted over a longer duration and with repeated sessions. To support this, Guardini et al. [7] reported of a significant increase in knowledge during evaluation of an educational program which involved seven pain education sessions held over a nine-month period. In addition, Ellis et al., Biceck, and De Rond et al. [18] [19] [26] stress that content on comprehensive pain education for nurses' should include areas of pain theory, physiology of pain, pain assessment methods, attitudes, values, and different pain interventions. Pain education may therefore be more effective if comprehensive pain education was conducted over a longer duration and with regular updates. With improved knowledge, it is anticipated that adequate pain assessment and treatment by nurses may be conducted appropriately.

Secondly, regardless of deficiencies in pain education sessions, lack of knowledge of use of pain assessment scales, for example, could be associated with unavailability of the scales in the hospital as was discovered during the study. Literature regarding pain assessment scales is however inconclusive. While it was reported that inadequate pain assessment resulted from lack of pain assessment scales [6] [27] and [28], others found no difference in pain assessment practices in the presence of pain scales [29] [30], while other nurses reported of good pain assessment practices even in the absence of a pain assessment scale [31]. Inconsistencies indicate the need to introduce pain scales and educate nurses with demonstrations and supportive supervision on their use.

Lack of demonstrations and support through practicing under supervision is therefore a third factor that could have affected nurses' knowledge and attitudes. Demonstrations have been found to be an effective way of facilitating clinical teaching of psychomotor and observational skills to nurses [32]. This may however, only be effective if appropriate and user friendly scales are introduced in the setting. This is necessary because it was reported that children were unable to understand the Faces scale when attempts to use it were made. While some researchers have argued that a universally acceptable Faces Pain Scale-Revised (FPS-R) can be used on children of any cultural and ethnic orientation [2] [33], other studies have demonstrated that any version of the Faces scale can be used in any context without problems. One research supports findings from this study that sometimes a crying face that always represents severe pain in the Faces scale may not reflect the actual pain severity because some children would not cry even when in severe pain [34]. Pain experts in collaboration with peadiatric nurse specialists need to develop a culturally appropriate and user friendly tool that should take into consideration ease of use and time spent assessing a single child for pain considering the chronic nurse shortage and high patient census in the department. The use of this tool should then be demonstrated to nurses and then followed up with supportive supervision to enhance its application. 
It was further noted that nurses had lack of knowledge of the WHO analgesic ladder. Nurses' lack of knowledge of the ladder implies that appropriate analgesics were not given to children according to pain severity. Lack of knowledge of the ladder among nurses and doctors is similarly reported in other studies [35] [36]. Consequently, education of nurses about, and implementation of the WHO analgesic ladder, led to the improvement in prescription and administration of analgesics three months after the intervention was reported [35]. Nurses therefore need to be educated more on the ladder, which should include the current version of the ladder as updated by the World Health Organisation (WHO). WHO has updated the guidelines to replace the 3-step analgesic ladder with a 2 -step one aimed at treating persisting pain in children with various medical conditions including cancer [37]. According to the World Health Organization [37], the guidelines exclude the second step due to lack of evidence of usefulness of codeine phosphate and tramadol in treating pain in children with moderate pain. Once nurses have been trained, it is recommended that copies of the ladder be posted on all children's wards for reference. Some research findings have emphasized that knowledge alone may be incomplete until the guidelines are made available and accessible to nurses and then they are shown how to use them to treat pain when identified [38] [39].

The study also revealed positive attitudes towards pain, pain assessment and treatment including use of morphine in children. Similar findings have been reported elsewhere [15] [40]. Unfortunately, positive attitudes are not always reflected in practice, with some nurses demonstrating fear of side effects and others just feeling that morphine use in children is not necessary. These fears and feelings have also been documented [4] [15] and [41]. Current evidence however shows that morphine addiction is unlikely in children when using oral morphine [12] [42]. Furthermore, research has shown that neonates and older children experience the same side effects and that morphine administration to all children is safe [43]. Nurses' concerns therefore may reflect a lack of knowledge, and resistance to change, since all trainings had a session on morphine use. As such, nurses may benefit from supportive supervision by those with experience so they appreciate that morphine could safely be administered to children. This is strongly supported for development of knowledge and skills and influencing positive practices in the clinical area [44] [45]. This may work to promote nurses' motivation to using morphine in children.

\section{Conclusion/Implication}

This study showed that nurses have knowledge about pain assessment and treatment, though some gaps exist. Additionally, a few negative attitudes were still prevalent especially in use of morphine in children. It is not surprising then that pain management among children was inadequate. These findings may reflect on the quality of pain education the nurses received, unavailability of pain scales and lack of support to link theory with practice. Nurse leaders and training facilitators are challenged to create more opportunities for comprehensive 
and longer pain education sessions for nurses. Furthermore, user friendly pain assessment scales need to be developed, and nurses educated and demonstrated on their use, with opportunities for supportive supervision in the clinical setting for nurses to link theory and practice. It is hoped that implementation of such strategies will significantly improve the management of pain and consequently improve outcomes of care for children in Malawi.

\section{Study Limitations}

This was a small academic study conducted in one hospital with few nurses who were purposively sampled. Findings may therefore be limited to this setting. However, it does provide some valuable insight into issues affecting the management of pain in Malawian children.

In addition, most nurses who attended a pain education workshop in 2009 and pain management of burns in children were either unavailable or refused to participate. Results therefore may have been biased towards palliative care issues. The researcher feels participation of those nurses may have provided a balance in the results.

\section{Acknowledgements}

All authors for their contributions and Malawi Government for funding the first author as part of Masters studies.

\section{References}

[1] Kituyi, W.P., Imbaya, K.K., Wambani, J.O., Sisenda, T.M. and Kuremu, R.T. (2011) Postoperative Pain Management: Clinicians' Knowledge and Practices on Assessment and Measurement at Moi Teaching and Referral Hospital. East and Central African Journal of Surgery, 16, 20-24.

[2] Walters, M.A. (2009) Commentary: Pain Assessment in Sub-Saharan Africa. Pediatric Pain Letter, 11, 1-5.

[3] Gaughan, D.M., Hughes, M.D., Searge, G.R., Selwyn, P.A., Carey, V.J., et al. (2002) The Prevalence of Pain in Pediatric Human Immunodeficiency Virus/Acquired Immunodeficiency Syndrome as Reported by Participants in the Pediatric Late Outcomes Study (PACTG 219). Pediatrics, 109, 1144-1154.

https://doi.org/10.1542/peds.109.6.1144

[4] Matthew, P.J., Matthew, J.L. and Singh, S. (2011) Knowledge, Attitudes and Practices of Pediatric Critical Care Nurses towards Pain: A Survey in a Developing Country Setting. Journal of Postgraduate Medicine, 57, 196-200. https://doi.org/10.4103/0022-3859.85203

[5] Wang, H.-L. and Tsai, Y.-F. (2010) Nurses' Knowledge and Attitudes: Nurses' Knowledge and Barriers Regarding Pain Management in Intensive Care Units. Journal of Clinical Nursing, 19, 3188-3196. https://doi.org/10.1111/j.1365-2702.2010.03226.x

[6] Rampanjato, R.M., Florence, M., Patrick, N.C. and Finucane, T. (2007) Factors Influencing Pain Management in Emergency Departments in Central Africa. Emergency Medical Journal, 24, 475-476. https://doi.org/10.1136/emj.2006.045815

[7] Guardini, I., Talamini, R., Fioriko, F., Lirutti, M. and Palese, A. (2008) The Effec- 
tiveness of Continuing Education in Post-Operative Pain Management: Results from a Follow-Up Study. The Journal of Continuing Education in Nursing, 39, 281288. https://doi.org/10.3928/00220124-20080601-08

[8] Larsen, D. (2007) Pain Management in Nursing. What Does It Mean? Pain-Talk. http://www.pain-talk.org.uk

[9] Middleton, C. (2004) Barriers to the Provision of Effective Pain Management. Nursing Times, 100, 42-45.

[10] Hockenberry, M.J. and Wilson, D. (2009) Wong's Essential Pediatric Nursing. Clinical Companion. 8th Edition, Mosby Elsevier, St. Louis.

[11] Voepel-Lewis, T., Zannotti, G., Dammeyer, J.A. and Merkel, S. (2010) Reliability and Validity of the Face, Legs, Activity, Cry, Consolability Behavioural Tool in Assessing Acutely Ill Patients. American Journal of Critical Care, 19, 55-61. https://doi.org/10.4037/ajcc2010624

[12] Namukwaya, E., Leng, M., Downing, J. and Katabira, E. (2011) Cancer Pain Management in Resource Limited Settings: A Practice Review. Pain Research and Treatment, 2011, Article ID: 393404. https://doi.org/10.1155/2011/393404

[13] Melzack, R. and Wall, P.D., Eds. (2003) Handbook of Pain Management. A Clinical Companion to Wall and Melzack's Textbook of Pain. Churchill Livingstone, Edinburg.

[14] Simons, J. and Roberson, E. (2002) Poor Communication and Knowledge Deficits: Obstacles to Effective Management of Children's Postoperative Pain. Journal of Advanced Nursing, 40, 78-86. https://doi.org/10.1046/j.1365-2648.2002.02342.x

[15] Melhuish, S. and Payne, H. (2006) Nurses' Attitudes to Pain Management during Routine Venepuncture in Young Children. Paediatric Nursing, 18, 20-23. https://doi.org/10.7748/paed.18.2.20.s19

[16] Albertyn, R., Rode, H., Millar, A.J.W. and Thomas, J. (2009) Challenges Associated with Paediatric Pain Management in Sub Saharan Africa. International Journal of Surgery, 7, 91-93. https://doi.org/10.1016/j.ijsu.2009.01.005

[17] Bates, J., Gwyther, L. and Dinat, N. (2008) Morphine, Friend of Foe? Malawian Medical Journal, 20, 112-114.

[18] Ellis, J.A., McCleary, L., Blouin, R., Dube, K., Rowley, B., et al. (2007) Implementing Best Practice Pain Management in a Pediatric Hospital. Journal of Specialists in Pediatric Nursing, 12, 264-277. https://doi.org/10.1111/j.1744-6155.2007.00121.x

[19] De Rond, M.E.J., de Wit, R., van Dam, F.S.A.M., van Campen, B.T.M., den Hartog, Y.M. and Klievink, R.M.A. (2000) A Pain Monitoring Program for Nurses: Effects on Nurses' Pain Knowledge and Attitude. Journal of Pain and Symptom Management, 19, 457-467. https://doi.org/10.1016/S0885-3924(00)00128-7

[20] Anderson, R. (2007) Thematic Content Analysis: Descriptive Presentation of Qualitative Data.

http://rosemarieanderson.com/wp-content/uploads/2014/08/ThematicContentAnal ysis.pdf

[21] Braun, V. and Clarke, V. (2006) Using Thematic Analysis in Psychology. Qualitative Research in Psychology, 3, 77-101.

http://eprints.uwe.ac.uk/11735 https://doi.org/10.1191/1478088706qp063oa

[22] Latimer, M.A., Johnston, C.C., Ritchie, J.A., Clarke, S.P. and Gilin, D. (2009) Factors Affecting Delivery of Evidence-Based Procedural Pain Care in Hospitalized Neonates. Journal of Obstetric, Gynaecologic and Neonatal Nursing, 38, 182-194. https://doi.org/10.1111/j.1552-6909.2009.01007.x 
[23] Mitchell, A. and Boss, B.J. (2002) Adverse Effects of Pain on the Nervous System of Newborn and Young Children: A Review of Literature. Journal of Neuroscience Nursing, 34, 228-236. https://doi.org/10.1097/01376517-200210000-00002

[24] O’Brien, S., Dalton, J.A., Konsler, G. and Carlson, J. (1996) The Knowledge and Attitudes of Experienced Oncology Nurses Regarding the Management of CancerRelated Pain. Oncology Nursing Forum, 23, 515-521.

[25] Howell, D., Butler, L., Vincent, L., Watt-Watson, J. and Stearns, N. (2000) Influencing Nurses Knowledge Attitudes and Practice in Cancer Pain Management. Cancer Nursing, 23, 55-63. https://doi.org/10.1097/00002820-200002000-00009

[26] Biceck, E. (2004) Nurses Attitudes, Knowledge and Use of Non-Pharmacological Pain Management Techniques and Therapies Paper 12. Honors Project, Illinois Wesleyan University. http://digitalcommons.iwu.edu/nursing_honproj/12

[27] Hossain, Md.S., Wiroonpanich, W. and Orapiriyakul, R. (2010) Nurses' Knowledge, Attitudes, and Pain Management Practice of Post-Operative Children in Bangladesh. Paper presented at the 2 nd International Conference on Humanities and Social Sciences, Prince of Songkla University, Bangladesh, April 2010. http://kb.psu.ac.th/psukb/bitstream/2010/7826/1/325999.pdf

[28] Hockenberry-Eaton, M., Barrera, P., Brown, M., Bottomley, S.J. and O’Neil, J.B. (1999) Pain Management in Children with Cancer. Austin, Texas.

[29] Wickistrom Ene, K. (2008) Postoperative Pain: Predictors, Barriers and Outcomes. Doctoral Dissertation, Institute of Health and Care Sciences, University of Gothenburg.

[30] Jacob, E. and Puntillo, K.A. (1999) A Survey of Nursing Practice in the Assessment and Management of Pain in Children. Paediatric Nursing, 25, 278-286.

[31] Polkki, T., Korhonen, A., Laukkala, H., Saarella, T., Vehvilainen-Julkunen, K. and Ptetila, A.M. (2010) Nurses' Attitudes and Perceptions of Pain Assessment in Neonatal Intensive Care. Scandinavian Journal of Caring Science, 24, 49-55. https://doi.org/10.1111/j.1471-6712.2008.00683.x

[32] Finley G.A., Forgeron, P.A. and Arnaout, M. (2008) Action Research: Developing a Pediatric Cancer Pain Program in Jordan. Journal of Pain Symptom Management, 35, 447-454. https://doi.org/10.1016/j.jpainsymman.2007.05.006

[33] Chambers, C.T. and Craig, K.D. (1998) An Intrusive Impact of Anchors in Children's Faces Pain Scales. Pain, 78, 27-37. https://doi.org/10.1016/S0304-3959(98)00112-2

[34] Srouji, R., Ratnapalan, S. and Schneeweis, S. (2010) Pain in Children: Assessment and Non-Pharmacological Pain Management. International Journal of Pediatrics, 2010, Article ID: 474838. https://doi.org/10.1155/2010/474838

[35] World Health Organisation (2012) Persisting Pain in Children. Highlights for Policy Makers Extracted from WHO Guidelines on the Pharmacological Treatment of Persisting Pain in Children with Medical Illnesses. World Health Organisation, Geneva.

[36] Weddell, R. (2004) Improving Pain Management for Patients in a Hospital Burns Unit. Nursing Times, 100, 38-40.

[37] Ribeiro, M.C.O., Pereira, C.U., Umberto, C., Sallum, A.M.C., Alves, A.B., et al. (2012) Knowledge of Doctors and Nurses on Pain in Patients Undergoing Craniotomy. Revista Latino-Americana de Enfermagem, 20, 1057-1063. https://doi.org/10.1590/s0104-11692012000600007

[38] Gimbler-Berglund, I., Ljusegren, G. and Enskar, K. (2008) Factors Influencing Pain Management in Children. Paediatric Nursing, 20, 21-24. 
https://doi.org/10.7748/paed.20.10.21.s25

[39] Curtis, K.M., Henriques, H.F., Fanciullo, G., Reynolds, C.M. and Suber, F. (2007) A Fentanyl-Based Pain Management Protocol Provides Early Analgesia for Adult Trauma Patients. Journal of Trauma-Injury Infection \& Critical Care, 63, 819-826. https://doi.org/10.1097/01.ta.0000240979.31046.98

[40] Da Cruz, I.C.F. (2010) Demonstrations and Nursing Clinical Teaching-Systematic Literature Review. Online Brazilian Journal of Nursing, 9.

http://www.objnursing.uff.br https://doi.org/10.5935/1676-4285.20102837

[41] Size, M., Soyannwo, N.A. and Justin, D.M. (2007) Pain Management in Developing Countries. Anaesthesia, 62, 38-43. https://doi.org/10.1111/j.1365-2044.2007.05296.x

[42] Gielen, J., Gupta, H., Rajvanshi, A., Bhatnagar, S., Mishra, S., Chaturved, A.K., Vander Banden, S. and Broechkaert, B. (2011) The Attitudes of Indian Palliative Care Nurses and Physicians to Pain Control and Palliative Care Sedation. Indian Journal of Palliative Care, 17, 33-41. https://doi.org/10.4103/0973-1075.78447

[43] Kart, T., Christrup, L. and Rasmussen, M. (1997) Recommended Use of Morphine in Neonates, Infants and Children Based on a Literature Review: Part 2-Clinical Use. Pediatric Anesthesia, 7, 93-101. https://doi.org/10.1111/j.1460-9592.1997.tb00488.x

[44] Kipkorir, C. (2011) Knowledge and Attitudes of Nurses towards Pain Management among the Elderly: A Case Study of Registered Nurses from Local Health Centres, Kokkola. Unpublished Thesis, University of Applied Sciences, Central Osrobothnia.

[45] Hyrkas, K., Appelqvist-Schmidleschner, K. and Kiimaki, K. (2004) First-Line Managers' Views of the Long Term Effects of Clinical Supervision: How Does Clinical Supervision Support and Develop Leadership in Health Care? Journal of Nursing Management, 13, 209-220. https://doi.org/10.1111/j.1365-2834.2004.00522.x 


\section{Appendix A: Interview Guide}

\section{Demographic information}

Respondent's Number Date of Interview

Ward Currently working in Year of qualification

Highest qualification attained

How many years have you worked in the Paediatric ward?

\section{Knowledge of Pain Management}

What are your responsibilities related to pain management in this ward?

Tell me about the training you went through in relation to pain management. What specifically did you learn about? How has this learning helped in your role of managing pain?

Tell me what you know about managing pain in children

\section{Probes}

How do you assess for pain in children in your ward?

Tell me how you treat pain when it is identified in children

Can you explain to me about the WHO analgesic ladder for pain management for children?

What areas do you still feel you need to know about pain management?

Attitudes towards pain and pain management in children

What are your views about pain in children?

\section{Probes}

What is your opinion about children's feelings of pain?

What do you think about children's ability to explain how much pain they are feeling?

Please tell me your views about the use of pain assessment scales in pain identification

Faces scale

FLACC scale for pain assessment in children

Tell me your views about giving morphine to children

Tell me about your experience in giving morphine to children during you years of working with children?

What are your views about current pain management practices in this ward/unit?

In your opinion, is enough being done in your ward to keep children free from pain?

Probe: What, in your opinion, hinders you from managing pain in children effectively? 
Submit or recommend next manuscript to SCIRP and we will provide best service for you:

Accepting pre-submission inquiries through Email, Facebook, LinkedIn, Twitter, etc. A wide selection of journals (inclusive of 9 subjects, more than 200 journals)

Providing 24-hour high-quality service

User-friendly online submission system

Fair and swift peer-review system

Efficient typesetting and proofreading procedure

Display of the result of downloads and visits, as well as the number of cited articles Maximum dissemination of your research work

Submit your manuscript at: http://papersubmission.scirp.org/

Or contact jbm@scirp.org 